\title{
DNA markers for Typhula resistance in timothy (Phleum pratense L.)
}

\author{
Pirjo Tanhuanpää ${ }^{1}$, Mika Isolahti², Oiva Nissinen³ ${ }^{3}$ Outi Manninen² \\ ${ }^{1}$ Green Technology, Natural Resources Institute Finland (Luke), Myllytie 1, FI-31600 Jokioinen, Finland \\ ${ }^{2}$ Boreal Plant Breeding Ltd, Myllytie 10, Fl-31600 Jokioinen, Finland \\ ${ }^{3}$ MTT Agrifood Research Finland, Eteläranta 55, 96300 Rovaniemi, Finland \\ email: pirjo.tanhuanpaa@luke.fi
}

\begin{abstract}
The objective of the study was to find DNA markers associated with resistance to Typhula ishikariensis in timothy (Phleum pratense L.) using bulked-segregant analysis. A progeny of $161 \mathrm{~F}_{1}$ individuals was created by crossing the Finnish resistant cultivar Tammisto II with the Japanese susceptible cultivar Nosappu. Six to ten clones of each $\mathrm{F}_{1}$ individual were tested for resistance in the greenhouse, and a survival index, which was based both on survival and the ability of plants to recover, was calculated for each $F_{1}$ to describe resistance. Resistant and susceptible bulks of eight individuals in each were screened with a total of 292 primer combinations. Six DNA markers were found to be associated with resistance, together explaining $15 \%$ of phenotypic variation in Typhula resistance. Four of the markers formed one linkage group, which contained a QTL explaining 7\% of the variation in Typhula resistance.
\end{abstract}

Key words: bulked segregant analysis (BSA), DNA markers, disease resistance, Phleum pratense, timothy, Typhula ishikariensis

\section{Introduction}

Timothy (Phleum pratense L.) is a perennial grass species grown in temperate regions of Europe, North America and Asia, and it is the most important forage grass in Nordic countries. In northern Finland, agriculture is based on livestock and most of the cultivated area is used for growing grass forage. The cultivated form of timothy is hexaploid, but its genomic composition has not been fully resolved yet. However, there is some evidence that the genome is allohexaploid, containing four doses of the bertolonii genome and two doses of the rhaeticum genome (Stewart et al. 2011). Both of these genomes derive from the same progenitor and are not well differentiated which explains that both hexasomic and tetradisomic inheritance has been reported in timothy (Stewart et al. 2011).

The main goals in timothy breeding are high yield, forage quality, and winter survival. Winter injuries are caused both by abiotic and biotic factors. The major causes for poor overwintering are low-temperature parasitic fungi. Typhula ishikariensis Imai (syn. T. idahoensis Remsb.), speckled snow mold, is one of the most important pathogens in the cold climates of the northern hemisphere (Smith et al. 1989), including northern Finland (Mäkelä 1981). The occurrence of fungi and the extent of damage vary greatly from year to year due to climatic conditions; thick and prolonged snow cover and unfrozen soil favor the existence of fungi (Jamalainen 1974). The damage might not occur every year but, on the other hand, total losses of the ley might occur (Jamalainen 1974). Besides graminaceous plants, T. ishikariensis can attack clover, alfalfa, winter turnip, rape, sugar beets, and bulbs of iris and tulip (Ekstrand 1955, Procenko 1967).

Use of fungicides and appropriate cultivation techniques reduce fungal injuries, but the most efficient solution would be the improvement of resistance. Heritability estimates for resistance towards snow molds are high in grasses (Gauder 1994). There is great genetic variation in resistance (Jamalainen 1974) and it is highly dependent on a plant's degree of cold hardening; cold hardened plants are more resistant both to biotic and abiotic winter injuries (Tronsmo 1984). In resistance breeding, recognition of resistant individuals is laborious, time-consuming, and expensive. Therefore, the use of suitable molecular markers for phenotyping (MAS = marker-assisted selection) would ease the work of breeders. Markers associated with resistance can be identified by QTL (quantitative trait locus) mapping or using bulked-segregant analysis (BSA) (Michelmore et al. 1991). With BSA, DNA markers tightly linked with genes underlying monogenic traits or major genes underlying quantitative traits can be found. BSA has been used to uncover resistance genes in several crop species (Muyelle et al. 2005, Han et al. 2014, Takahashi et al. 2014), including polyploids (Zhang et al. 2014, Wang et al. 2016) and also using dominant markers (Asnaghi et al. 2004). MAS has also successfully been applied in breeding programs for transferring resistance loci in different crops (Farokhzadeh and Fakheri 2014). 
No linkage map for a hexaploid timothy $(2 n=6 x=42)$ exists yet and we did not want to construct one. Therefore, we aimed to identify DNA markers (SSRs = simple sequence repeats; AFLPs = amplified fragment length polymorphisms; REMAPs = retrotransposon-microsatellite amplified polymorphisms; SRAPs = sequence-related amplified polymorphisms) associated with Typhula resistance in timothy using BSA. To our knowledge, AFLPs and SRAPs have not been used in timothy before.

\section{Materials and methods}

\section{Plant material}

The selection of crossing parents was based on a previous study (unpublished results), which was conducted within MTT Agrifood Research Finland (nowadays: Natural Resources Institute Finland), at Lapland Research Station in Rovaniemi $\left(66^{\circ} 35^{\prime} \mathrm{N}\right.$ lat). That study contained timothy individuals from North American, Middle European, and Scandinavian cultivars, and from the breeding material of Boreal (Boreal Plant Breeding Ltd., Finland), from which we selected contrasting phenotypes for the crossing parents. One parent was an individual from cultivar Tammisto II (Boreal Plant Breeding Ltd.), which was Typhula resistant but with a weak cold tolerance, and the other was an individual from a Japanese cultivar Nosappu (Ueda et al. 1977), which was susceptible but cold tolerant. Tammisto II has also previously been shown to have resistance against T. ishikariensis (Jamalainen 1974). The parents were crossed in a greenhouse by putting inflorescences from one individual of each parent cultivar together in the same pollination bag. Seeds were collected from these two parents, and an $F_{1}$ progeny of 161 individuals was sown. Each $\mathrm{F}_{1}$ plant was vegetatively propagated by dividing the clump into parts in order to get 10 clones for a resistance test. This was not always possible, so the number of clones varied from 6 to 10 .

DNA was extracted using the method of Tinker et al. (1993) with modifications described in Tanhuanpää and Manninen (2012). DNA concentrations were measured using the GeneQuant II RNA/DNA Calculator (Pharmacia Biotech Ltd., Cambridge, UK).

\section{Speckled snow mold resistance testing}

Resistance tests were carried out at MTT Agrifood Research Finland, Lapland Research Station. Fungal isolates were collected in the spring from naturally infected timothy plantlets in the field. Sclerotia were surface-sterilized in $70 \%$ ethanol and pure-cultured on potato dextrose agar plates at $8^{\circ} \mathrm{C}$. One isolate was randomly selected, and it was also grown on autoclaved wheat kernels for 7-8 weeks for obtaining sclerotia. In the resistance tests we used inoculum which consisted of both dried sclerotinia and suspension of mycelium.

The $F_{1}$ clones, which were grown in pots filled with a commercial fertilized soil mixture with brown peat and perlite, 80:20, were cold-hardened outdoors in September-October. Following cold-hardening, the pots were put on trays, from 72 to 99 plants per tray, 20 trays altogether, and individuals were randomized on the trays. Clones from the same $F_{1}$ were located on different trays, but not all genotypes were represented on each tray (randomized incomplete block design). Inoculation was done by spreading dried sclerotia ( $5 \mathrm{ml}$ per tray) on the soil and spraying suspension of mycelium and agar (12 g mycelium and agar in $200 \mathrm{ml}$ water per tray) on the leaves. To imitate snow cover and to keep high humidity, infected plantlets were covered with moist cotton ( $200 \mathrm{~g}$ per tray, $300 \mathrm{ml}$ water), and the trays were wrapped in plastic and transferred to a growth chamber at $1-2{ }^{\circ} \mathrm{C}$. The progress of the disease and the condition of the plantlets were visually observed, and the test was ended when the differences between genotypes were most obvious and the disease had reached the demanded level of severity (when about half of the plants had died). This took about 2.5 months after which cotton was removed and the plantlets were transferred to a greenhouse for recovery at $\sim 12{ }^{\circ} \mathrm{C}$ and $8 \mathrm{~h}$ light per $24 \mathrm{~h}$. The viability of plantlets was thereafter observed three times in January with one week's intervals.

A survival index was calculated for each $\mathrm{F}_{1}$ individual to describe resistance, and it consisted of two indices: index 1 , which was based on survival of the plants, and index 2, which was based on the ability of plants to recover. For index 1 , the percentage of survived clones from each $F_{1}$ individual was counted, whereafter the values obtained were ranked so that an individual with the highest percentage $(90 \%)$ got a value of 1 , the second highest a value of 2 , and so on up to 24 (no clones alive). For index 2, viability was observed three times. If a clone was dead on the first observation date, it got a value of 0 , if a clone was alive on the first date but not thereafter, it got a value of 1 , and if a clone was alive on the third date, it got a value of 3 . The means of the values from the clones of each $F_{1}$ individual were calculated and ranked from 1 (best survival) to 21 . Indices 1 and 2 were summed for survival index, which varied from 2 to 45 . 


\section{Bulking of $\mathrm{F}_{1}$ individuals}

Based on the survival index, 8 most resistant (survival index 2-10) and 8 most susceptible $F_{1}$ individuals (survival index 43-45) were selected and their DNAs were pooled in equal proportions to create a resistant and a susceptible bulk, respectively.

\section{Markers}

Retrotransposon based REMAP markers detect polymorphisms in amplification products generated between retrotransposons and microsatellites (Kalendar et al. 1999, Kalendar and Schulman 2006). Five different retrotransposon-based primers were used, they were designed by cloning retrotransposon regions from grasses, identifying long terminal repeats (LTRs), and choosing conserved motifs at or near their termini. The microsatellite-based primers contained repeat units (composed of two or three bases) anchored at their $3^{\prime}$ ends by a single nucleotide. REMAP markers were amplified in a reaction volume of $20 \mu \mathrm{l}$, using $1 \mathrm{U}$ Biotools DNA polymerase (Biotools B\&M Labs, S.A., Madrid, Spain), with the buffer containing $2 \mathrm{mM} \mathrm{MgCl}$, supplied by the enzyme manufacturer, $200 \mu \mathrm{M}$ each dNTP, $500 \mathrm{nM}$ each primer, and $25 \mathrm{ng}$ DNA. The PCR program used is described in Tanhuanpää et al. (2016). Amplification products were resolved on a $1.4 \%$ agarose gel (GellyPhor ${ }^{\circledR}$ LE, Euroclone S.p.A, Pero, Italy).

SRAP markers are amplified from open reading frames (Li and Quiros 2001) using forward primers ('me') preferentially annealing to exonic regions and reverse primers ('em') to intronic regions and promoters. SRAP analyses were carried out as described in Tanhuanpää et al. (2007). Primer sequences are presented in Budak et al. (2004). AFLP analysis was based on the method of Vos et al. (1995) using restriction enzymes EcoRI and Msel, and is described in Tanhuanpää et al. (2008) with a minor modification for timothy: $5 \mu \mathrm{l}$ from the 1:50 diluted preamplified reaction was used as a template DNA for selective amplifications. Twenty-seven timothy SSRs (Cai et al. 2003) were amplified and analyzed as described in Tanhuanpää and Manninen (2012), treating each SSR allele as a separate locus.

All the PCRs were run in a PTC-220 DNA Engine Dyad ${ }^{\mathrm{TM}}$ Peltier Thermal Cycler (MJ Research, Waltham, MA, USA). The forward primers in SRAP, SSR and AFLP analyses were labeled with a fluorescent dye, FAM (5-carboxyfluorescein), TET (6-carboxytetrachlorofluorescein) or HEX (hexachloro-6-carboxyfluorescein), and amplification products were resolved and visualized on a MegaBACE ${ }^{\mathrm{TM}} 500$ Sequencer (GE Healthcare, Buckinghamshire, UK). In marker names, the size of the marker is shown after an underline.

REMAPs were first tested on the two bulks and the parents, and thereafter, promising markers were tested on individual plants of the bulks. Other marker types were tested directly on the individual plants of the bulks and parents. Putative candidate markers for resistance were further analyzed in the whole progeny of $161 \mathrm{~F}_{1}$ individuals.

\section{Statistical analyses}

Data from resistance test were analyzed statistically using the Proc MIXED function in SAS 6.11 (SAS Institute Inc., Cary, USA) and the association of each marker with Typhula resistance was evaluated by regression analysis using Proc REG in SAS 9.3. Multiple regression analysis was used to calculate joint effects of several markers. Joinmap 3.0 (Van Ooijen and Voorrips 2001) was used for determining linkages between markers using a LOD (logarithm of odds) score of 4.0. Map distances in cM were calculated by Kosambi's mapping function (Kosambi 1944). The NQTL program version 26-Nov-2001 (Windows version of MQTL, Tinker and Mather 1995) was used for QTL analysis. One-thousand permutations were made to estimate a threshold for type-l error rate below $5 \%$, which was at a test statistic of 5.8. The segregation of markers was tested against an expected 1:1 ratio for a simplex marker in an $F_{1}$ progeny of a hexaploid species using the $\chi^{2}$ test in the JoinMap program.

\section{Results and discussion}

The frequency distribution of a survival index, which describes Typhula resistance, in the timothy $\mathrm{F}_{1}$ progeny is presented in Figure 1 a. The mean of the index was $28.4 \pm 10.6$. There were six completely susceptible $F_{1}$ progeny, all clones of which were dead after the resistance test (survival index $=45$ ). On the other hand, the most resistant $\mathrm{F}_{1}$ contained only one dead clone (survival index $=2$ ). 
a)

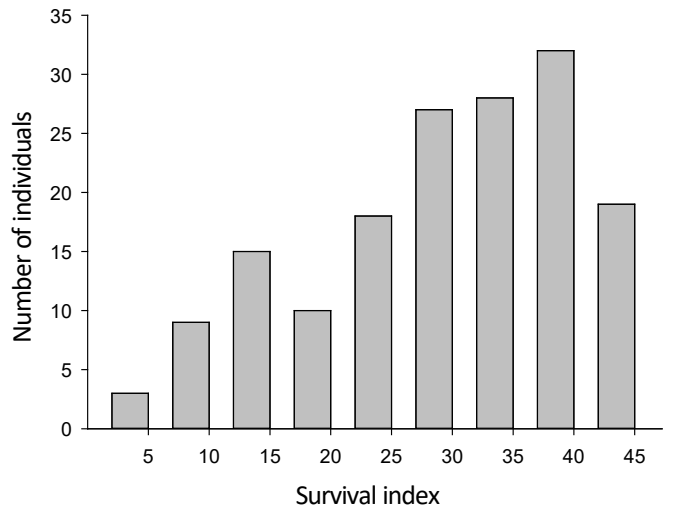

b)

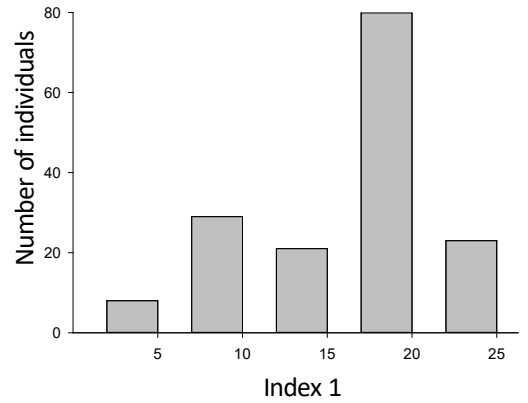

c)

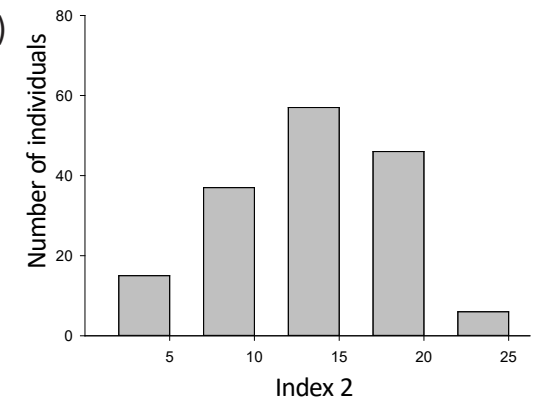

Fig.1. Frequency distribution of survival index (a), which describes Typhula resistance ( 2 meaning totally resistant), in the $F_{1}$ progeny of the timothy cross Tammisto II x Nosappu. Resistance tests were made on 6-10 clones of each $F_{1}$ individual. The survival index is the sum of two different indices: $b$ ) index 1 , which describes plant survival, and c) index 2 , which describes the ability of plants to recover from the disease.

Ninety REMAP, 36 SRAP, and 139 AFLP primer combinations, and 27 SSRs, were analyzed in the bulks and the parents. Markers that were amplified from Tammisto II and the resistant bulk were regarded putatively associated with resistance. Likewise, markers that were amplified from Nosappu and the susceptible bulk were regarded putatively associated with susceptibility (non-visible allele associated with resistance). Eight promising markers (1 REMAP, 5 AFLPs, 2 SRAPs) were analyzed in the whole progeny of 161 individuals. Of these, the REMAP (F02197_810; amplified with primers CCCCCTCTAGGCGACATCC and (AC) 9 T), 4 AFLPs (ACG-CGA_351, ATA-CCC_326, CAT-CTC_116, GC-CCC_183) and one SRAP (me4em10_95) were associated with Typhula resistance with $p<0.05$ (Table 1), and the visible marker alleles were derived from Tammisto II. According to multiple regression analysis, these six markers together explained 15\% of phenotypic variation in Typhula resistance.

Four of the six markers showed distorted segregation $(p<0.05)$. Except in me4em10_95, the distortion was towards the Nosappu allele (no amplification) and is probably due to problems in amplification. Another possibility is that some individuals originated from self-pollination in the Nosappu parent, although this probability is low in timothy (7-8\%, Nielsen and Smith 1959), which causes depression of vigor and decrease in fertility (Nilsson 1934). Based on all available marker information we could rule out the possibility of self-pollination in all but twelve individuals. The segregation of me4em10_95 fits either 4:1 or 3:1 ratios, which would be expected for a duplex marker respectively in an autohexaploid or an allohexaploid (Jones 1967).

In linkage analysis, two separate marker groups were found. The four AFLP markers formed one strong group (17.4 cM) with pairwise LODs for linkages over 16, which contained a QTL for resistance with a test statistic of 12.4, corresponding to a LOD score of 2.7 (Fig. 2; the test statistic multiplied by 0.22 gives the LOD score value, Tinker and Mather 1995). Because the QTL curve was quite flat, the exact location of the QTL remained unresolved, but the nearest ( $4.4 \mathrm{cM}$ ) marker to the QTL was GC-CCC_183. The QTL is a minor locus explaining 7\% of the variation in resistance. The REMAP marker F02197_810 and the SRAP me4em10_95 were linked to each other with a genetic distance of $43 \mathrm{cM}$. However, estimation of genetic distances between dominant simplex and duplex markers is very poor (Grivet et al. 1996); therefore, we don't know if these markers are associated with the same resistance locus or two different loci. Thus, besides the QTL in the AFLP linkage group, we found at least one additional locus for Typhula resistance segregating in our $\mathrm{F}_{1}$ progeny. 
Table 1. Putative markers associated with speckled snow mold resistance in the $F_{1}$ progeny of the timothy cross Tammisto II $x$ Nosappu. Associations were analyzed with regression analysis.

\begin{tabular}{lccccccccc}
\hline & \multicolumn{3}{c}{ presence in the bulks $^{\mathrm{b}}$} & \multicolumn{3}{c}{ survival index $^{\mathrm{e}}$} \\
\hline Marker name $^{\mathrm{a}}$ & Type & resistant & susceptible & $\mathrm{n}^{\mathrm{c}}$ & $\chi^{2 \mathrm{~d}}$ & marker band & no band & $\mathrm{p}^{\mathrm{f}}$ & $\mathrm{R}^{2 \mathrm{~g}}$ \\
me4em10_95 & SRAP & 8 & 2 & 156 & $51.9^{* * *}$ & $26.9 \pm 10.8$ & $33.7 \pm 8.8$ & 0.001 & 0.067 \\
ACG-CGA_351 & AFLP & 7 & 1 & 155 & $7.0^{* *}$ & $24.8 \pm 11.4$ & $30.7 \pm 9.6$ & $<0.001$ & 0.075 \\
ATA-CCC_326 & AFLP & 6 & 1 & 141 & $8.7^{* *}$ & $25.3 \pm 11.1$ & $29.7 \pm 10.0$ & 0.016 & 0.041 \\
CAT-CTC_116 & AFLP & 6 & 1 & 156 & 2.6 & $25.8 \pm 10.5$ & $30.6 \pm 10.1$ & 0.005 & 0.051 \\
GC-CCC_183 & AFLP & 6 & 1 & 159 & $8.6^{* *}$ & $24.9 \pm 11.2$ & $30.6 \pm 9.7$ & $<0.001$ & 0.069 \\
F02197_810 & REMAP & 6 & 1 & 155 & 0 & $25.4 \pm 10.5$ & $31.2 \pm 10.2$ & $<0.001$ & 0.075 \\
\hline
\end{tabular}

${ }^{a}=$ marker name with the size of the band indicated; ${ }^{b}=$ presence of the marker band in the eight individuals of each bulk; ${ }^{\mathrm{c}}=$ the number $^{\mathrm{a}}$ of $F_{1}$ individuals producing marker phenotypes; ${ }^{d}=$ segregation of markers in the progeny tested against an expected $1: 1$ ratio with significance: ${ }^{* *}<0.01,{ }^{* *}<0.001 ;{ }^{e}=$ survival index in the two marker phenotype classes of $\mathrm{F}_{1}$ individuals; ${ }^{\mathrm{f}}=$ probability of the association of a marker with Typhula resistance; ${ }^{\mathrm{g}}=$ fraction of phenotypic variation in resistance explained by each marker individually

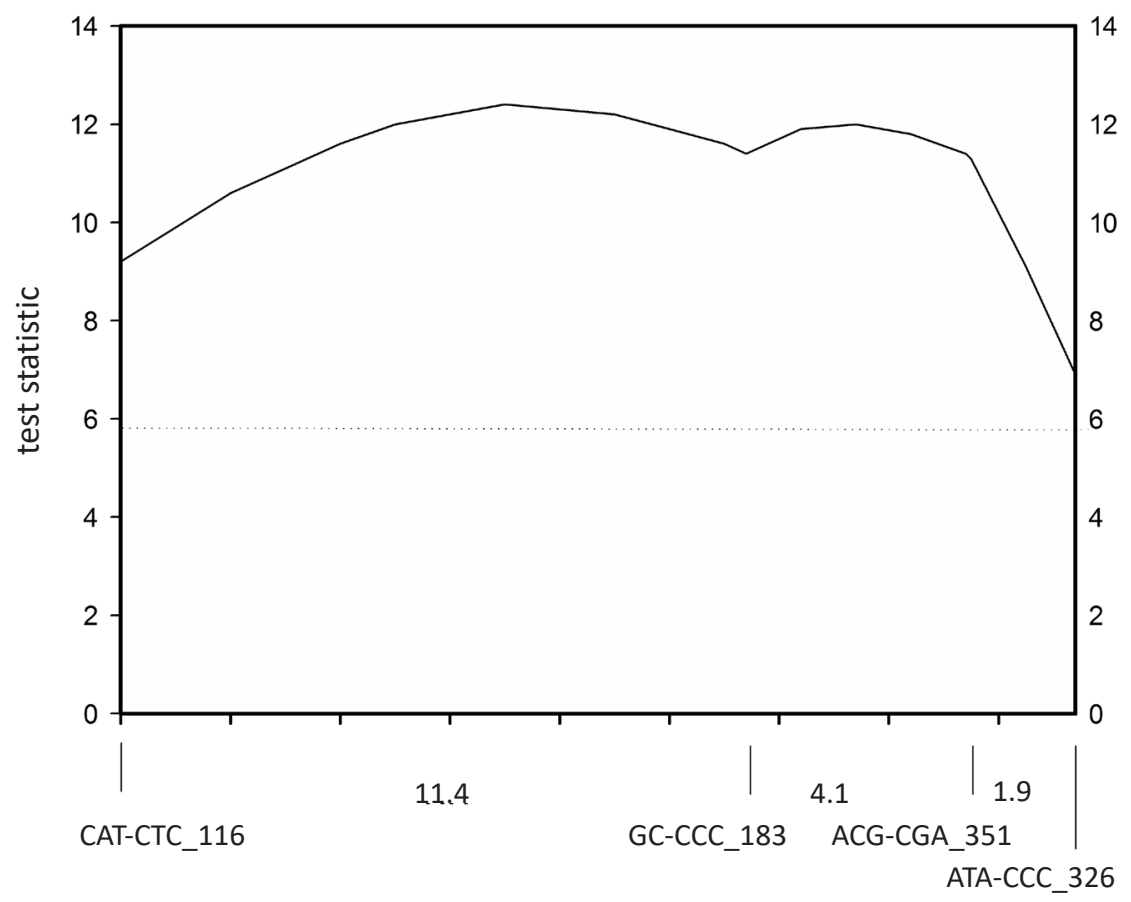

Fig.2. QTL likelihood map of a linkage group harboring a locus for Typhula resistance in the $\mathrm{F}_{1}$ progeny of the timothy cross Tammisto II $x$ Nosappu. The dashed line indicates the test statistic threshold of 5.8 .

If individuals from the timothy $F_{1}$ progeny were selected based on them having Tammisto II alleles in all the six markers associated with Typhula resistance, we would end up with 24 individuals with a survival index of $22.7 \pm$ 10.5 , whereas the mean of the index in the whole progeny was $28.4 \pm 10.6$. On the other hand, approximately the same survival index (23.0 \pm 10.8 in 38 individuals) would be achieved using only two markers: one marker from the AFLP linkage group, e.g. GC-CCC_183, and REMAP F02197_810.

Mapping of resistance genes is challenging; to reveal as many regions associated with resistance as possible, many markers, a large number of segregating progeny, and very accurate phenotypic data are needed. Because only $15 \%$ of the phenotypic variation in Typhula resistance could be explained by the markers found in our study, many resistance loci remained undiscovered. One reason for this was that genes from Nosappu that increase winter hardiness affect biotic resistance as well, but we only looked for markers associated with resistance that were derived from Tammisto II. 
No markers for Typhula resistance have been previously found in timothy. In a related species, creeping bentcrass (Agrostis stolonifera L.), also only minor loci were found: one QTL which explained 9\% of the phenotypic variation in resistance, and the other that affected recovery rate after Typhula infection explaining $7 \%$ of the variation (Zhang et al. 2012). If the markers associated with Typhula resistance found in our study were to be used in MAS, they should be converted into easily scorable SCAR (sequence characterized amplified region) markers.

\section{Acknowledgements}

The authors wish to thank Anneli Virta, Leena Ramstedt, Sirpa Moisander, Kirsti Mäkelä, Hanna Kuusela, and the staff at Natural Resources Institute Finland, Lapland Research Station for excellent technical assistance. Ruslan Kalendar is thanked for designing retrotransposon primers, Alan Schulman for revising the language, and Marja Jalli for her valuable comments on the description of the resistance test. The Ministry of Agriculture and Forestry in Finland is acknowledged for the financial support of the study.

\section{References}

Asnaghi, C., Roques, D., Ruffel, S., Kaye, C., Hoarau, J.-Y., Télismart, H., Girard, J.C., Raboin, L.M., Risterucci, A.M., Grivet, L. \& D'Hont, A. 2004. Targeted mapping of sugarcane rust resistance gene (Bru1) using bulked segregant analysis and AFLP markers. Theoretical and Applied Genetics 108: 759-764.

Budak, H., Shearman, R.C., Parmaksiz, I., Gaussoin, R.E., Riordan, T.P. \& Dweikat, I. 2004. Molecular characterization of Buffalograss germplasm using sequence-related amplified polymorphism markers. Theoretical and Applied Genetics 108: 328-334.

Cai, H.W., Yuyama, N., Tamaki, H. \& Yoshizawa, A. 2003. Isolation and characterization of simple sequence repeat markers in the hexaploid forage grass timothy (Phleum pratense L.). Theoretical and Applied Genetics 107: 1337-1349.

Ekstrand, H. 1955. Höstsädens og vallgräsens övervintring. Statens Växtskyddsanstalt. Meddelande 67: 1-125. (in Swedish).

Farokhzadeh, S. \& Fakheri, B.A. 2014. Marker-assisted selection for disease resistance: applications in breeding (review). International Journal of Agriculture and Crop Sciences 7: 1392-1405.

Gauder, D.A. 1994. Progress towards understanding interactions between cold hardiness and snow mold resistance and development of resistant cultivars. Canadian Journal of Plant Pathology 16: 241-246.

Grivet, L., D’Hont, A., Roques, D., Feldmann, P., Lanaud, D. \& Glaszmann, J.C. 1996. RFLP mapping in cultivated sugarcane (Saccharum spp.): Genome organization in a highly polyploid and aneuploid interspecific hybrid. Genetics 142: 987-1000.

Han, X., Yang, Y., Wang, X., Zhou, J., Zhang, W., Yu, C., Cheng, C., Cheng, Y., Yan, C. \& Chen, J. 2014. Quantitative trait loci mapping for bacterial blight resistance in rice using bulked segregant analysis. International Journal of Molecular Sciences 15: 11847-61.

Jamalainen, E.A. 1974. Resistance in winter cereals and grasses to low-temperature parasitic fungi. Annual Review of Phytopathology 12:281-302.

Jones, A. 1967. Theoretical segregation ratios of qualitatively inherited characters for hexaploid sweetpotato (Ipomoea batatas). USDA Technical Bulletin 1368: 1-6.

Kalendar, R., Grob, T., Regina, M., Suoniemi, A. \& Schulman, A. 1999. IRAP and REMAP: two new retrotransposon-based DNA fingerprinting techniques. Theoretical and Applied Genetics 98: 704-711.

Kalendar, R. \& Schulman, A.H. 2006. IRAP and REMAP for retrotransposon-based genotyping and fingerprinting. Nature Protocols 1: 2478-2484.

Kosambi, D.D. 1944. The estimation of map distance from recombination values. Annals of Eugenics 12: 172-175.

Li, G. \& Quiros, C.F. 2001. Sequence-related amplified polymorphism (SRAP), a new marker system based on a simple PCR reaction: its application to mapping and gene tagging in Brassica. Theoretical and Applied Genetics 103: 455-461.

Michelmore, R.W., Paran, I. \& Kesseli, R.V. 1991. Identification of markers linked to disease-resistance genes by bulked segregant analysis: a rapid method to detect markers in specific genomic regions by using segregating populations. Proceedings of the National Academy of Sciences of the United States of America 88: 9828-9832.

Muyelle, H., Baert, J., Van Bockstaele, E., Moerkerke, B., Goetghebeur, E. \& Roldán-Ruiz, I. 2005. Identification of molecular markers linked with crown rust (Puccinia coronata f. sp. Iolii) resistance in perennial ryegrass (Lolium perenne) using AFLP markers and a bulked segregant approach. Euphytica 143: 135-144.

Mäkelä, K. 1981. Winter damage and low-temperature fungi on leys in North Finland in 1976-1979. Acta Agraria Fennica 20 : 102-131.

Nielsen, E.L. \& Smith, D.C. 1959. Chlorophyll inheritance patterns and extent of natural self-pollination in timothy. Euphytica 8: 169-179.

Nilsson, F. 1934. Studies in fertility and inbreeding in some herbage grasses. Hereditas 19: 1-162.

Procenko, E.P. 1967. Typhula borealis Ekstrand infesting tulips in the U.S.S.R. Mikologiya i Fitopatologiya 1: 107-109.

Smith, J.D., Jackson, N. \& Woolhouse, A.R. 1989. Fungal diseases of amenity turf grasses. 3rd ed. London: E. \& F.N. Spon. 401 p.

Stewart, A.W., Joachimiak, A.J. \& Ellison, N.W. 2011. Phleum. In: Kole, C. (ed.). Wild crop relatives: genomic and breeding resources. Millets and grasses. Springer-Verlag Berlin Heidelberg. p. 257-274. 
Takahashi, W., Miura, Y., Sasaki, T. \& Takamizo, T. 2014. Identification of a novel major locus for gray leaf spot resistance in Italian ryegrass (Lolium multiflorum Lam.). BMC Plant Biology 14: 303.

Tanhuanpää, P., Kalendar, R., Schulman, A.H. \& Kiviharju, E. 2007. A major gene for grain cadmium accumulation in oat (Avena sativa L.). Genome 50: 588-594.

Tanhuanpää, P., Kalendar, R., Schulman, A.H. \& Kiviharju, E. 2008. The first doubled haploid linkage map for cultivated oat. Genome 51: 560-569.

Tanhuanpää, P. \& Manninen, O. 2012. High SSR diversity but little differentiation between accessions of Nordic timothy (Phleum pratense L.). Hereditas 149: 114-127.

Tanhuanpää, P., Erkkilä, M., Kalendar, R., Schulman, A. \& Manninen, O. 2016. Assessment of genetic diversity in Nordic timothy (Phleum pratense L.). Hereditas 153:5.

Tinker, N.A., Fortin, M.G. \& Mather, D.E. 1993. Random amplified polymorphic DNA and pedigree relationships in spring barley. Theoretical and Applied Genetics 85: 976-984.

Tinker, N.A. \& Mather, D.E. 1995. MQTL: software for simplified composite interval mapping of QTL in multiple environments. Journal of Applied Genetics 1:2. http://wheat.pw.usda.gov/jag/.

Tronsmo, A.M. 1984. Predisposing effects of low temperature on resistance to winter stress factors in grasses. Acta Agriculturae Scandinavica 34: 210-220.

Ueda, S., Masutani, T., Higuchi, S., Furuya, M. \& Tsutsui, S. 1977. New timothy variety 'Nosappu'. Bulletin of the Hokkaido Prefec-tural Agricultural Experiment Station 38:34-46. (in Japanese, with English abstract).

Van Ooijen, J.W. \& Voorrips, R.E. 2001. Joinmap ${ }^{\circledR}$ 3.0, Software for the calculation of genetic linkage maps. Plant Research International, Wageningen, The Netherlands.

Vos, P., Hogers, R., Bleeker, M., Reijans, M., van de Lee, T., Hornes, M., Frijters, A., Pot, J., Peleman, J., Kuiper, M. \& Zabeau, M. 1995. AFLP: a new technique for DNA fingerprinting. Nucleic Acids Research 23: 4407-4414.

Wang, Y.J., Wang, C.Y., Quan, W., Jia, X.J., Fu, Y., Zhang, H., Liu, X.L., Chen, C.H. \& Ji, W.Q. 2016. Identification and mapping of PmSE5785, a new recessive powdery mildew resistance locus, in synthetic hexaploid wheat. Euphytica 207: 619-626.

Zhang, T., Ge, M., Ye, X., Bughrara, S.S. \& Zhao, H. 2012. Construction of a linkage map for quantitative trait loci associated with economically important traits in creeping bentgrass (Agrostis stolonifera L.). Euphytica 188: 347-360.

Zhang, T., Yu, L.-X., McCord, P., Miller, D., Bhamidimarri, S., Johnson, D., Monteros, M.J., Ho, J., Reisen, P. \& Samac, D.A. 2014. Identification of molecular markers associated with verticillium wilt resistance in alfalfa (Medicago sativa L.) using high-resolution melting. PloS ONE 9: e115953. 